JOURNAL DE PHYSIQUE

Colloque C6, supplément au $n^{\circ} 12$, Tome 42, décembre 1981

page $\quad 6-235$

\title{
A STUDY OF THE GROUND STATE OF ACCEPTORS IN SILICON FROM THERMAL
}

\section{TRANSPORT EXPERIMENTS}

A.M. De Goër, M. Locatelli and K. Lassmann*

Service des Basses Températures, Laboratoire de Cryophysique, Centre d'Etudes Nucléaires de Grenoble, $85 X, 38041$ Grenoble Cedex, France

* Physikaliaches Institut, University of Stuttgart, 7000 Stuttgart 80, F.R.G.

ABSTRACT - Thermal conductivity measurements of silicon crystals doped with $B$ or In have shown the presence of several phonon scattering processes. The resonant effect observed below $1 \mathrm{~K}$ is ascribed to the existence of a distribution of splittings $N(\delta)$ of the $\Gamma_{8}$ ground state of the acceptor, which could be related to the presence of oxygen and carbon impurities. In two cases, the maximum of $\mathrm{N}(\delta)$ occurs for $\delta \max$ near $6 \mathrm{GHz}$, in agreement with previous ultrasonic studies $\left(\delta_{\max }>4 \mathrm{GHz}\right)$.

Samples and Experiments - The thermal conductivity of four Si single crystals doped with $B$ or In has been measured from $50 \mathrm{mK}$ to $200 \mathrm{~K}$. Three crystals have been studied by ultrasonic absorption in Stuttgart and some of these results have been already published [1]. The characteristics of the samples are given in table 1 .

TABLE 1

\begin{tabular}{|c|c|c|c|c|}
\hline Sample & S $80 \mathrm{~g}$ & S $87 \mathrm{~d}$ & S 52 & $\mathrm{~S} 33^{*}$ \\
\hline $\begin{array}{l}\text { Dimensions } \\
(\mathrm{mm} \times \mathrm{m} m \times \mathrm{mm})\end{array}$ & $2.6 \times 3.0 \times 35$ & $3.0 \times 3.0 \times 34$ & $2.3 \times 3.0 \times 14$ & $0.85 \times 3.03 \times 11$ \\
\hline Acceptor & B & B & In & In \\
\hline$\rho(\Omega \mathrm{cm})$ & 10.8 & 2.5 & 0.1 & 2 \\
\hline$N_{A}\left(\mathrm{~cm}^{-3}\right)$ & $1.210^{15}$ & $5.410^{15}$ & $5.10^{17}$ & $5.10^{15}$ \\
\hline$n_{0}\left(\mathrm{~cm}^{-3}\right)$ & $5.710^{17}$ & $\leqslant 2.10^{15}$ & $8.10^{17}$ & $7.10^{17}$ \\
\hline$n_{c}\left(\mathrm{~cm}^{-3}\right)$ & $4.110^{16}$ & $\leqslant 5.10^{15}$ & $?$ & ? \\
\hline $\begin{array}{l}\text { Growth method } \\
\delta_{\text {max. }}(\mathrm{GHz}) \\
\text { (from ul trasonics) }\end{array}$ & $\begin{array}{l}C z \\
\geq 4\end{array}$ & $\begin{array}{c}\text { F1. zone } \\
1.3\end{array}$ & $\begin{array}{l}C 2 \\
>4\end{array}$ & - \\
\hline
\end{tabular}

* This sample has been measured previously above $1.2 \mathrm{~K}$ [2]

Results and qualitative discussion - The experimental results are displayed in fig.1 in a $\log -\log$ plot and show that three temperature ranges can be considered.

(i) $T<2 K$ Resonant phonon scattering is present in the three samples measured in this temperature range. We ascribe this scattering to a direct process between the two energy levels arising from the ${ }^{8} 8$ acceptor ground state, the splitting being variable from site to site due to random strains and electric fields. The distri- 

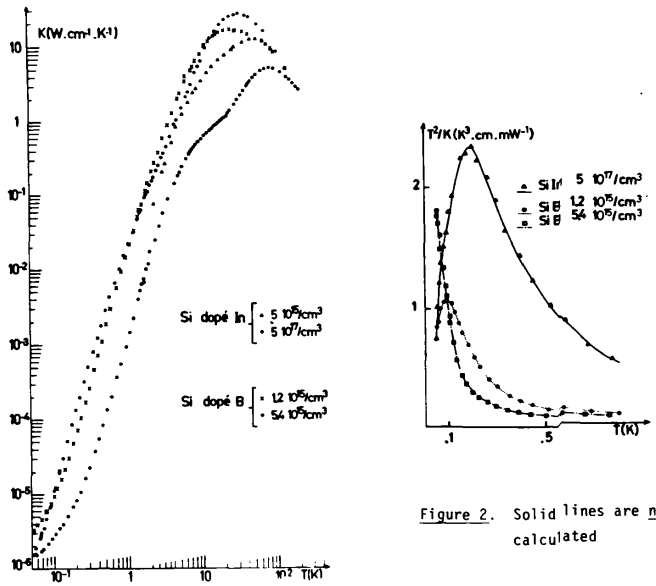

Figure 2. Solid lines are not calculated

\section{Figure 1.}

butions $N(\delta)$ have been studied at frequencies less than $4 \mathrm{GHz}$ by ultrasonic attenuation and related to the presence of carbon or oxygen impurities in the crystals [1]. The phonon relaxation rate due to this process is given approximatively by :

$$
\tau^{-1}(\omega)=\pi \bar{D}^{2} \omega N(\delta=\omega) / \pi \rho v^{2}
$$

where $\bar{D}$ is a mean value of the coupling constant, and the qualitative shape of $N(\delta)$ is given by the function $T^{2} / K$ [3]. In fig. $2, T^{2} / K$ is plotted as a function of $T$ for the three samples studied. A maximum is observed near $0.19 \mathrm{~K}$ in the case of $\mathrm{Si}$ : In $\left(5.10^{17} / \mathrm{cm}^{3}\right)$ and $0.09 \mathrm{~K}$ in the case of $\mathrm{Si}: \mathrm{B}\left(1.210^{15} / \mathrm{cm}^{3}\right)$, which would corres pond very crudely to frequencies $\delta_{\max }$ of 15 and $7 \mathrm{GHz}$ respectively. In the case of $\mathrm{Si}$ : $\mathrm{B}\left(5.10^{15} / \mathrm{cm}^{3}\right)$ the maximum is not reached at the lowest temperatures, so that $\delta_{\max }$ must be less than $4 \mathrm{GHz}$. These results are in very good qualitative agreement with those obtained by ultrasonic measurements and given in table 1.

(ii) $2<T<30 \mathrm{~K}$ A very clear dip appears near $20 \mathrm{~K}$ in the case of the In-doped samples, which has been already observed and attributed to an excited Jahn-Teller level of the acceptor near $40 \mathrm{~cm}^{-1}$ [2]. A small effect could be present near $3 \mathrm{~K}$ in the more highly doped $S i$ : B sample so that the ratio of the transition energies for 
the two systems would be about 5 , a value noticeably larger than previously supposed [4].

(iii) $I>30 \mathrm{~K}$ The dip near $40 \mathrm{~K}$ present in the lightly doped $\mathrm{Si}: \mathrm{B}$ crystal and not in the highly doped one is attributed to the presence of isolated oxygen interstitials ; the two crystals contain different amount of oxygen (see table 1 ) and in fact, the two curves cross near $20 \mathrm{~K}$. This resonant scattering observed near $40 \mathrm{~K}$ is also probably present in the In-doped samples and could be related to a transition near $80 \mathrm{~cm}^{-1}$, in reasonable agreement with the energy level scheme of oxygen deduced from FIR absorption measurements [5].

Quantitative analys is - A preliminary analys is of the results in the temperature range $T<1 \mathrm{~K}$ for the two samples containing oxygen and carbon has been carried out within the Debye approximation. Only boundary scattering $\left(\tau_{B}{ }^{-1}=\right.$ constant $)$ and scattering by the acceptors as described by equation (1) have been considered. We have used an expression of $N(\delta)$ which gives a satisfactory description of the distribution obtained by a Monte-Carlo calculation for point defects such as carbon [1]. The general features of the experimental $T^{2} / K$ curves (fig.2) can be described by such an analysis and, with the parameters given in table 2, the position and intensity of the maximum are well reproduced, but not the detailed shape of the curves. The values of $\delta_{\max }$ obtained from these fits are similar in the two crystals, in contrast with the crude estimations from the position of the pics given above.

\section{TABLE 2}

\begin{tabular}{|c|c|c|c|c|}
\hline Sample & $\delta_{\max }(\mathrm{GHz})$ & $\mathrm{N}_{\mathrm{A}} \overline{\mathrm{D}}^{2}\left(\mathrm{erg}^{2} \mathrm{~cm}^{-3}\right)$ & $\mathrm{N}_{\mathrm{A}}\left(\mathrm{cm}^{-3}\right)$ & $\overline{\mathrm{D}}(\mathrm{eV})$ \\
\hline $\mathrm{Si}: \mathrm{B}(\mathrm{S} 80 \mathrm{~g})$ & $6.2 \pm 0.4$ & $6.510^{-9}$ & $1.210^{15}$ & 1.5 \\
$\mathrm{Si}:$ In (S 52) & $5.6 \pm 0.4$ & $5.110^{-7}$ & $5.10^{17}$ & 0.63 \\
\hline
\end{tabular}

This analysis also gives values of $N_{A} \bar{D}^{2}$ and, supposing that all the acceptors contribute to the scattering, we obtain the values of $\bar{D}$ given in table 2 , which are not unreasonable. Full details will be published elsewhere.

\section{References}

[1] LASSMANN K, and ZEILE $H$. in "Phonon Scattering in Condensed Matter" edited by MARIS H.J., Plenum Press (1980), 369.

[2] DE COMBARIEU $A$, and LASSMANN $K$. in "Phonon Scattering in Solids" edited by CHALLIS L.J. et al., Plenum Press (1976), 340.

[3] CHALLIS L.J., DE GOER A.M. and HASELER S.C., Phys. Rev. Letter 39 (1977) 558.

[4] SIGMUND E. and LASSMANN $K$. in "Phonon Scattering in Condensed Matter" edited by MARIS H.J., Plenum Press (1980) 417.

[5] HAYES W. and BOSOMWORTH D.R., Phys. Rev. Letters 23 (1969), 851. 